\title{
Comparative study of gonococcal arthritis and Reiter's syndrome
}

\author{
E. R. HURD, J. JOHNS, AND A. CHUBICK \\ From the Southwestern Medical School, Dallas, Texas, USA
}

Differentiation between Reiter's syndrome (RS) and gonococcal arthritis may be difficult, since both conditions are characterised by arthritis and urethritis. Holmes and coworkers ${ }^{156}$ noted that 13 out of 23 patients who later developed RS were initially thought to have gonococcal arthritis, and both diseases are by no means virtually exclusive. Patients with culture-positive gonococcal urethritis sometimes go on suffering from an aseptic peripheral arthritis unresponsive to antiboitics. Many of them are then found to be HLA-B27 positive and then respond well* to anti-inflammatory drugs, suggesting a diagnosis of RS. While these diseases may occasionally be confused, differences in the skin lesions, the clinical course, and the presence of non-gonococcal conjunctivitis usually differentiate them eventually.

\section{Comparison of clinical features}

We have recently compared the clinical features of 123 patients with gonococcal arthritis with those of 12 patients with RS. These patients were hospitalised in Parkland Memorial Hospital, Dallas, Texas, over the five years 1972-7 (Tables 1, 2, 3). Patients with gonococcal arthritis tended to be younger (mean age 23) than patients with RS (mean age 31). In the gonococcal arthritis group $65 \%$ were females; the RS group consisted entirely of males. Interestingly $69 \%$ of the gonococcal arthritis group was black; most of the RS group were white. It is also interesting that all the white patients with RS were positive for HLA-B27 while the two black patients tested were B27-negative.

Patients with gonococcal arthritis were admitted quickly. The mean duration of their symptoms before admission was only $6 \cdot 3$ days as against a median of 28 days in patients with RS. One RS patient had a chronic intermittent course of 18 years. The incidence of migratory polyarthralgias was higher in the gonococcal arthritis group and there was a slightly higher incidence of fever in *This is not everybody's experience-Editor.
Table 1 Demographic and clinical features of 123 patients with gonococcal arthritis and 12, with Reiter's syndrome admitted to hospital 1972-7

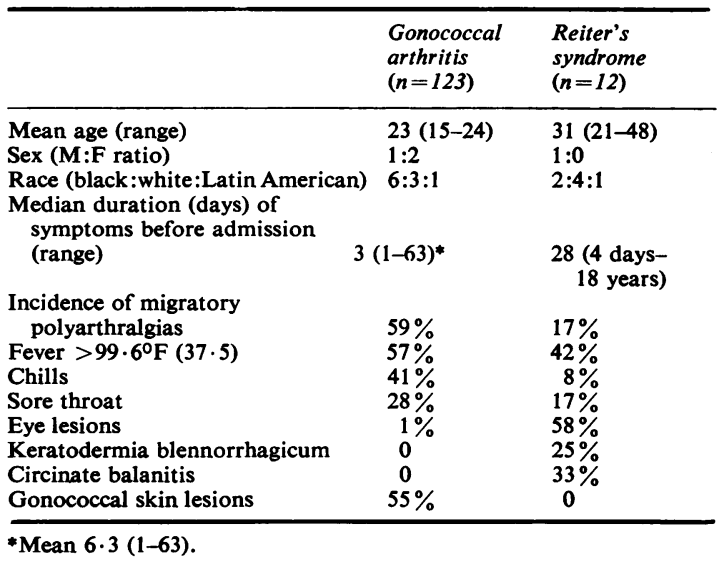

Table 2 Laboratory findings in 123 patients with gonococcal arthritis and 12 with Reiter's syndrome

\begin{tabular}{|c|c|c|c|c|}
\hline \multirow[b]{3}{*}{$\begin{array}{l}\mathrm{WBC} / \mathrm{mm}^{3} \\
\% \mathrm{PMN} \\
\mathrm{HCT} \\
\text { ESR }(\mathrm{mm} \text { in } 1 \mathrm{~h})\end{array}$} & \multicolumn{2}{|c|}{$\begin{array}{l}\text { Gonococcal arthritis } \\
(n=123)\end{array}$} & \multicolumn{2}{|c|}{$\begin{array}{l}\text { Reiter's syndrome } \\
(n=12)\end{array}$} \\
\hline & Mean & Range & Mean & Range \\
\hline & $\begin{array}{l}11083 \\
68 \\
38 \cdot 5 \\
44\end{array}$ & $\begin{array}{l}(4900-27000) \\
(33-89) \\
(26 \cdot 1-51 \cdot 6) \\
(2-168)\end{array}$ & $\begin{array}{l}10675 \\
72 \\
41 \cdot 5 \\
68\end{array}$ & $\begin{array}{l}(7400-15400) \\
(68-82) \\
(33 \cdot 3-48 \cdot 5) \\
(26-98)\end{array}$ \\
\hline
\end{tabular}

Table 3 Analysis of synovial fluid in 123 patients with gonococcal arthritis and 12 with Reiter's syndrome

\begin{tabular}{|c|c|c|c|c|}
\hline & \multicolumn{2}{|c|}{ Gonococcal arthritis } & \multicolumn{2}{|c|}{ Reiter's syndrome } \\
\hline & Mean & Range & Mean & Range \\
\hline $\begin{array}{l}\text { Glucose } \\
\text { (mg/100 ml) }\end{array}$ & 59 & $(5-136)$ & 86 & $(67-100)$ \\
\hline Protein $(\mathrm{g} / 100 \mathrm{ml})$ & $4 \cdot 4$ & $(2 \cdot 0-6 \cdot 7)$ & $5 \cdot 6$ & $(4 \cdot 6-6 \cdot 3)$ \\
\hline $\begin{array}{l}\text { Culture and/or } \\
\text { Gram-stain }\end{array}$ & . & & 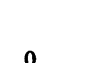 & \\
\hline $\begin{array}{l}\text { Culture positive } \\
\text { Gram-stain }\end{array}$ & $11 / 50$ & $(22 \%)$ & 0 & \\
\hline \begin{tabular}{l}
\multicolumn{1}{c}{ positive } \\
WBC $/ \mathrm{mm}^{3}$ \\
$\% \mathrm{PMN}$
\end{tabular} & $\begin{array}{l}3 / 12 \\
44885 \\
90\end{array}$ & $\begin{array}{l}(25 \%) \\
(1000-320000) \\
(58-100)\end{array}$ & $\begin{array}{l}0 \\
19595 \\
79\end{array}$ & $\begin{array}{l}(500-115000) \\
(65-90)\end{array}$ \\
\hline
\end{tabular}


these patients. The maximum temperature for the gonococcal arthritis group was $103^{\circ} \mathrm{F}\left(39 \cdot 4 \mathrm{C}^{\circ}\right)$ compared with $101^{\circ} \mathrm{F}\left(38 \cdot 3^{\circ} \mathrm{C}\right)$ in the $\mathrm{RS}$ group. The incidence of chills was considerably higher in the gonococcal arthritis patients.

Eye lesions were present in $58 \%$ of the RS patients, but only one gonococcal arthritis patient gave a history of transient conjunctivitis. Keratodermia blennorrhagica and circinate balanitis were present only in RS patients. Classical gonococcal skin lesions were noted in $55 \%$ of such patients and in none of the RS patients. These lesions are maculopapular and pustular in nature, often with necrotic centres. Moreover, the distribution of the skin lesions was highly typical. In nearly all cases $(97 \%)$ they were on the upper extremities, especially the arms and fingers. Lesions on the lower extremities were found in $75 \%$ and $47 \%$ had lesions on the trunk. Only one patient had skin lesions on the forehead.

\section{JOINTS AFFECTED}

Table 4 shows the pattern of joint and periarticular disease in the two groups of patients. The average number of joints involved per patient was two in the gonococcal arthritis group as against a mean of five in RS. Forty per cent of the gonococcal arthritis patients had monoarticular arthritis compared with none of the RS patients. The incidence of oligoarticular involvement was the same in both groups. While $67 \%$ of RS patients had four or more joints affected only $9 \%$ of the gonococcal arthritis group had polyarticular disease.

Table 4 Distribution of articular and periarticular disease in 123 cases of gonococcal arthritis and 12 of Reiter's syndrome

\begin{tabular}{lcc}
\hline & $\begin{array}{l}\text { Gonococcal } \\
\text { arthritis }\end{array}$ & $\begin{array}{l}\text { Reiter's } \\
\text { syndrome }\end{array}$ \\
\hline $\begin{array}{l}\text { Mean No. of joints affected } \\
\text { per patient (range) }\end{array}$ & $2(0-7)$ & $5(2-11)$ \\
$\begin{array}{l}\text { Monoarticular } \\
\text { Oligoarticular (2-3 joints) }\end{array}$ & $40 \%$ & - \\
Polyarticular ( $\geqslant 4$ joints) & $41 \%$ & $33 \%$ \\
Incidence of tenosynovitis: & $9 \%$ & $67 \%$ \\
$\quad$ Overall & $45 \%$ & $25 \%$ \\
$\quad$ Tenosynovitis alone & $10 \%$ & $-25 \%$ \\
$\quad$ Associated with arthritis & $35 \%$ & $25 \%$ \\
Knee & $39 \%$ & $75 \%$ \\
Ankle & $24 \%$ & $58 \%$ \\
Wrist & $31 \%$ & $33 \%$ \\
Elbow & $21 \%$ & $25 \%$ \\
Shoulder & $14 \%$ & $8 \%$ \\
Metacarpophalangeal & $10 \%$ & $8 \%$ \\
Proximal interphalangeal & $9 \%$ & $17 \%$ \\
Metatarsophalangeal & $5 \%$ & $33 \%$ \\
Sacroiliac & - & $33 \%$ \\
Lumbar spine & - & $33 \%$ \\
Cervical spine & - & $8 \%$ \\
Temporomandibular & - & \\
\hline
\end{tabular}

Tenosynovitis was present in $45 \%$ and $25 \%$ of patients respectively. In the gonococcal arthritis patients, however, it was predominantly of the dorsum of the hand or wrist, while in the RS patients it was exclusively of the Achilles tendon. Ten per cent of the gonococcal arthritis patients had tenosynovitis without specific joint involvement.*

The incidence of specific joint involvement in gonococcal arthritis and RS also showed some differences. Knees and ankles were affected more commonly in RS than in gonococcal arthritis, while wrists, elbows, shoulders, metacarpophalangeal, and proximal interphalangeal joints were similarly affected in the two groups. The metatarsophalangeal joints were affected more commonly in RS patients. The sacroiliac joints, lumbar spine, cervical spine, and temporomandibular joints were affected only in RS patients.

\section{LABORATORY FINDINGS}

The peripheral WBC count was slightly raised in both groups (Table 2). The highest count in the gonococcal arthritis group was $27000 / \mathrm{mm}^{3}(27 \times$ $\left.10^{9} / \mathrm{l}\right)$ and in the RS group $15400 / \mathrm{mm}^{3}(15.4 \times 8$ $\left.10^{9} / 1\right)$. The erythrocyte sedimentation rate (ESR) was higher in the RS patients.

The synovial fluid glucose tended to be lower in the gonococcal arthritis group (Table 3). In some patients it was as low as $5 \mathrm{mg} / 100 \mathrm{ml}$. Most RS patients had a normal synovial fluid glucose. The protein was higher in the RS group, although it was raised in both groups. Synovial fluid cultures were positive for gonococcus in $22 \%$ of cases. An additional three patients had a positive Gram stain. None of the RS patients had positive cultures. The WBC count in synovial fluid was considerably higher in gonococcal arthritis than in RS. The mean WBC count in the gonococcal group was $44885 / \mathrm{mm}^{3}$ $\left(44.8 \times 10^{9} / 1\right)$ with a maximum of $320000 / \mathrm{mm}^{3}$ $\left(320 \times 10^{9} / 1\right)$. The mean WBC count in the RS group was $19595 / \mathrm{mm}^{3}\left(19.6 \times 10^{9} / \mathrm{l}\right)$ with a maximum of $115000 / \mathrm{mm}^{3}\left(115 \times 10^{9} / 1\right)$. Both types of fluids had a predominance of neutrophils.

The diagnostic categories according to positive culture sites in the gonococcal arthritis patients are shown in Table 5. Twelve per cent had definite gonococcal arthritis as determined by positive cultures from synovial fluid, skin lesions, or blood. Thirty per cent were termed probable since they had positive cultures from the urethra, cervix, rectum, or pharynx. Fifty-eight per cent of patients had a negative culture and were thus designated as possible

*Which might be found equally in RS-Editor. 
Table 5 Distribution of patients according to positiveculture sites

\begin{tabular}{lll}
\hline Culture site positive & Category & $\%$ Patients \\
\hline Joint, skin, blood & Definite & 12 \\
Urethra, cervix, rectum, pharynx & Probable & 30 \\
None & Possible & 58 \\
\hline
\end{tabular}

Table 6 Incidence of positive culture in various sites in gonococcal arthritis patients

\begin{tabular}{lcc}
\hline & $\begin{array}{c}\text { No. positive/ } \\
\text { No. cultured }\end{array}$ & $\%$ Positive \\
\hline Cervix & $26 / 59$ & 44 \\
Vagina & $4 / 10$ & 40 \\
Urethra & $10 / 42$ & 24 \\
Rectum & $18 / 78$ & 23 \\
Synovial fluid & $11 / 50$ & 22 \\
Pharynx & $4 / 19$ & 21 \\
Skin lesions & $1 / 20$ & 5 \\
Blood & $2 / 82$ & 2 \\
\hline
\end{tabular}

cases. It should be emphasised, however, that all patients responded well to antibiotic treatment and none developed RS or any other form of chronic arthritis.

The incidence of positive culture in various sites in the gonococcal arthritis patients is shown in Table 6 . It is apparent that $44 \%$ of cultures of the cervix and $40 \%$ of vaginal cultures were positive. The urethral and rectal cultures were positive in $24 \%$ and $23 \%$ of cases respectively. As previously mentioned, $22 \%$ of synovial fluid cultures were positive. Interestingly, $21 \%$ of pharyngeal cultures also were positive. Only one of 20 cultures from skin lesions and $2 \%$ of blood cultures were positive.

\section{Differential diagnosis}

About five patients per 1000 admitted to Parkland Hospital have gonococcal arthritis. This represents about $14 \%$ of the arthritis cases seen. Most patients are young and the majority are black females. Migratory polyarthralgias are common and are often associated with chills, skin lesions, and tenosynovitis. Most patients have from one to three joints affected. Classical maculopapular or pustular skin lesions are common, especially on the extremities. Most patients respond rapidly to treatment with 10 million units of penicillin $G$ per day for three days. No patients had any type of residual deformity.

In contrast, patients with RS, at least in Parkland Hospital, are much less common and are predominantly white males. The majority had four or more joints involved. None had monoarticular arthritis. In addition to knees, ankles, and wrist the metatarsal, phalangeal, and sacroiliac joints, as well as lumbar spine, were affected in several. Several had keratodermia blennorrhagica and circinate balanitis, and eye lesions were common. All of the white patients were positive for HLA-B27, while the two black patients were negative. The course tended to be chronic in many patients.

Our results are very similar to those of other recent series. ${ }^{28,35,77,123,147,148,218,282}$ We suggest that at gonococcal arthritis and RS can easily be differentiated in the great majority of cases.

\section{General discussion}

PROF. T. BITTER: Was there only one case of arthritis among 1000 admissions for GC?

DR. HURD: Exact figures are not available in such a retrospective study. Migratory polyarthralgias, for example, might not have been recorded at admission.

PROF. W. MARTEL: In both gonococcal arthritis and RS the early $x$-ray changes are limited to the soft tissues, and to that extent it is impossible to differentiate them radiologically. However, I recently reviewed about 20 cases of confirmed gonococcal arthritis and in none was there structural damage. I attribute this to the fact that they all responded to penicillin and were treated promptly. When patients are not treated promptly we occasionally see structural changes, but these are different from what you expect in RS. In one patient there was cartilage destruction of the radialcarpal joint within two weeks. In another patient, incorrectly thought to have RS and hence not treated immediately, rapid destruction of the cartilage and development of what we interpreted as a small sequestrum led to the correct diagnosis of gonococcal arthritis of the knee. Such extensive, irreversible destruction of cartilage and subchondral bone, looking very much like pyogenic arthritis and appearing within two to three weeks, is not expected in RS. In fact, in that patient the focal sequestrum indicated an infective arthritis, very different from RS.

PROF. V. WRIGHT: The figures for gonococcal arthritis at the Johns Hopkins Hospital before penicillin was available show that some patients developed a destructive arthritis while others had a migratory polyarthritis, which returned to normality. PROF. A. F. GOOD: This may be hair-splitting, but there is no reason why a patient cannot have both a disseminated gonococcal infection and RS. There is a sobering German case report of a patient who had RS and a serious gonococcal infection of an eye concomitantly.

PROF. M. ZIFF: Gonococcal arthritis has changed. 
We used to see it almost exclusively in men. Now it is a disease of women. But we probably miss RS in women who get gonococcal arthritis. During the second world war, however, there was a hospital in Dallas for the treatment of arthritis in American soldiers. Dr Phil Hench was stationed there and described a disease (in the Annals of Internal Medicine) called 'postgonococcal rheumatism'. What that was is hard to say. It was probably Reiter's syndrome. At all events, it seems to have vanished from history.

DR. G. R. V. HUGHES: Dr. Wilson and I have recently analysed gonococcal polyarthritis in Jamaica, where it is the commonest acute polyarthritis. A sobering thought for those who are on criteria committees is that one-third of the cases of culture-proved GC polyarthritis in Jamaica fulfil the Jones criteria for rheumatic fever. 